\title{
How the andrological sector suffered from the dramatic Covid 19 outbreak in Italy: supportive initiatives of the Italian Association of Andrology (SIA)
}

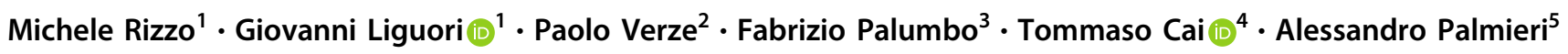

Received: 30 March 2020 / Revised: 9 April 2020 / Accepted: 9 April 2020 / Published online: 23 April 2020

(c) The Author(s), under exclusive licence to Springer Nature Limited 2020

The COVID-19 virus infection has led to a dramatic and very rapid health emergency in Italy. From the beginning of the epidemic to today (26 March 2020), Italy has the second-largest number of confirmed cases, after China.

Already in the first weeks of the emergency, measures of social distancing have been adopted at both national and regional level up to a progressive lockdown on the whole national territory, aimed at limiting the spread of the covid19 outbreak.

Among the very first measures adopted in the healthcare field, the suspension of all outpatient activities (except urgent ones) and a limitation of surgical activities exclusively to emergency and/or oncological interventions was imposed. Given the rapid aggravation of the epidemic, the same measures have also been extended to the private and mixed (private-public) healthcare sector [1].

Since Andrology deals with pathologies almost exclusively of an elected nature (if we exclude urgent conditions, such as torsion of the testicle, scrotal and penile traumas, testis and penile cancers) we can safely say that in an emergency context such as that it has come to be determined, the andrological discipline is basically in stand-by.

Michele Rizzo

mik.rizzo@gmail.com

1 Departmento of Urology, University of Trieste, Trieste, Italy

2 Urology Unit-Department of Medicine, Surgery, Dentistry "Scuola Medica Salernitana", University of Salerno, Salerno, Italy

3 San Giacomo Hospital, Monopoli, BA, Italy

4 Department of Urology, Santa Chiara Regional Hospital, Trento, Italy

5 Department of Neurosciences, Reproductive Sciences, Odontostomatology - Urology Unit, University of Naples "Federico II", Naples, Italy
International guidelines on essential/non-essential clinical activities, in fact, categorize Andrology as a non-essential one [2].

Andrologists who cannot regularly carry out their activity are on stand-by, but above all patients who cannot find an answer are on stand-by despite it is known that andrological pathologies have a very strong negative impact on the quality of life.

This criticality is relevant if we consider that to date it is not possible to predict the duration of the emergency, and the economic and organizational implications that may result from its resolution.

The possible strategies for the remodulation of the andrological activity were discussed and shared within a team of national experts belonging to the Italian Society of Andrology (SIA).

\section{Initiatives for andrologists}

With the various provisions of the Prime Minister that have followed all the national and local scientific meetings were canceled.

In order to compensate for this abrupt lack of opportunities for scientific meetings, a cycle of live reports was activated on YOUTUBE by recognized experts, to cover many different andrological topics.

The YOUTUBE channel was chosen as it can be easily followed by each member without having to download any streaming program, with the possibility to consult the contents without any time limitation.

\section{Initiatives for patients}

In this new context, non-urgent outpatient activities (such as Andrology) have been suspended throughout the national 
territory. The SIA wanted to give its tangible support to patients offering the possibility of receiving a free telephone consultation with a SIA representative, through an innovative project named "SIA replies to your medical questions". Being a telephone consultation, the project simply consists of listening to the patient, offering a useful consultation to resolve doubts about diagnostic or therapeutic paths already in progress, and which have been suspended due to the COVID-19 emergency.

For this purpose a dedicated telephone line has been set up and advertised through various press media, with the support of the SIA's press service.

Finally, with the contribution of the SIA's scientific committee a dedicated survey had been designed and implemented, in order to better understand whether a forced quarantine can impact on the overall quality of life, especially from a sexual point of view. This brief questionnaire was conceived to explore habits from both the Italian male and female population.

The activity of the SIA, therefore, took place internally towards the members and externally towards the patients. We believe this model can be successful in keeping an andrological activity alive even in difficult times as the one we are facing with the current COVID-19 outbreak.

\section{Compliance with ethical standards}

Conflict of interest The authors decare that they have no conflict of interest.

Publisher's note Springer Nature remains neutral with regard to jurisdictional claims in published maps and institutional affiliations.

\section{References}

1. Ficarra V, Novara G, Abrate A, Bartoletti R, Crestani A, De Nunzio C, et al. Urology practice during COVID-19 pandemic. Minerva Urol Nefrol. 2020. https://doi.org/10.23736/S0393-2249.20.03846-1.

2. Ribal MJ, Cornford P, Briganti A, Knoll T, Gravas S, Babjuk M, et al. EAU Guidelines Office Rapid Reaction Group: An organisation-wide collaborative effort to adapt the EAU guidelines recommendations to the COVID-19 era. https://uroweb.org/wp-content/uploads/EAUGuidelines-Office-Rapid-Reaction-Group-An-organisation-wide-colla borative-effort-to-adapt-the-EAU-guidelines-recommendations-to-theCOVID-19-era.pdf. 